\title{
Physical Development of 11-12-Year-Old Girls Involved in Swimming and Diving Physical
}

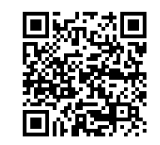

\author{
Evgenya Raspopova A* \\ Russian State University of Physical Culture, Sport, Youth and Tourism, Russia
}

Submission: September 06, 2019; Published: September 20, 2019

*Corresponding author: Evgenya Raspopova A, Russian State University of Physical Culture, Sport, Youth and Tourism, Russia

\begin{abstract}
Features of physical development largely determine the possibility of achieving high sports results in various sports. The study of morpho functional indicators of athletes of different specializations has long been one of the important areas of sports science. It is known that athletes of different specializations are distinguished by characteristic morpho functional signs and types of biological development that determine the growth rate of sports achievements. However, a comparison of the physique and physical development of girls involved in swimming and diving has not previously been carried out.
\end{abstract}

Material

The article presents a comparison of morpho functional indicators of girls of 11-12 years of age, engaged in swimming and diving, pupils of the SSR of Moscow. Research methods: anthropometry, fractionation of body weight, methods of statistical data processing. Results. The differences in physical development and the composition of the body weight of girl's jumpers in the water and swim 11-12 years. So, girls swimmers have higher rates of length and body weight, as well as chest girth, and jumpers in the water - the advantage of active body weight. Conclusion. The study revealed differences in the physical development of girls involved in swimming and diving from the age of 11 . These differences seem to be due to the influence of sports selection, on the one hand, and on the other sports training.

Keywords: Swimmers; Water jumpers; Physical development; Body proportions; Body mass composition

\section{Introduction}

The study of morphological and functional indicators of athletes of various specializations has long been one of the important areas of sports science. Many well-known scientists studied the physique of athletes [1,2]. The study of morphological and functional indicators helps to solve the main problems of modern sports, namely: - selection and determination of sports suitability in various sports [2-5] determination of growth rates and short-term prospects for individual age periods [6] orientation of residents of various regions in the choice of sports specialization, etc.

In recent years, a lot of material has been accumulated on the dynamics of the physical and biological development of athletes and the relationship with the growth rate of sports achievements has been shown [6,7]. However, a comparison of physique and physical development of girls involved in swimming and diving was not previously conducted. The goal was to determine the physique and physical development rate of girls, swimmers and jumpers in the water for 11-12 years.

\section{Research Objectives}

i. To study the features of the physical development of girls 11-12 years old, engaged in swimming and diving.

ii. Compare the body mass composition of girls 11-12 years old, engaged in swimming and diving.

iii. To identify the main differences in the physique of girls 11-12 years old, engaged in swimming and diving.

\section{Research methods and organization}

The study of the physical development and physique of girls aged 11-12 years was carried out by the method of anthropometry. The results are processed by methods of mathematical statistics. The average indices were calculated $\mathrm{X}$, standard deviations - $\sigma$, and the significance of differences in the average indices by Student t-test. The study was conducted based on the Moscow School of Education in 2016 - 17 years. The study involved girls of 11-12 years old, engaged in swimming and diving in the amount of 18 people in each age group. 


\section{The Results of the study}

A comparative analysis of the main indicators of physical development (Table 1) showed that the swimmers are 11-12 years old in length over their peers in the water. At 11 years of age, the difference is $6.4 \mathrm{~cm}$, and already at 12 years of age $-17.0 \mathrm{~cm}$. A comparison of the annual increments in body length from 1112 years allowed to establish higher values for representatives

Table 1: The main indicators of the physical development of girls 11-12 years old, engaged in swimming and diving.

\begin{tabular}{|c|c|c|c|c|}
\hline \multirow{2}{*}{ Indicators } & \multirow{2}{*}{ Age (years old) } & \multirow{2}{*}{$\begin{array}{c}\text { Swimming } \\
\qquad \mathrm{X} \pm \sigma\end{array}$} & Diving & \multirow[t]{2}{*}{$\mathbf{P}$} \\
\hline & & & $\mathrm{X} \pm \sigma$ & \\
\hline \multirow{2}{*}{ Body length $(\mathrm{cm})$} & 11 & $144,9 \pm 1,6$ & $138,5 \pm 4,9$ & $<0,05$ \\
\hline & 12 & $158,8 \pm 4,8$ & $141,8 \pm 4,7$ & $<0,01$ \\
\hline \multirow{4}{*}{ Body weight (kg) } & 11 & $34,6 \pm 0,7$ & $30,8 \pm 3,3$ & $<0,05$ \\
\hline & 12 & $46,2 \pm 1,3$ & $32,3 \pm 8,4$ & $<0,01$ \\
\hline & 11 & $71,3 \pm 1,2$ & $67,1 \pm 3,7$ & $<0,05$ \\
\hline & 12 & $82,1 \pm 4,8$ & $69,9 \pm 3,1$ & $<0,01$ \\
\hline \multirow[t]{2}{*}{ Chest circumference $(\mathrm{cm})$} & 11 & 10,3 & 7,8 & \\
\hline & 12 & 12,6 & 9,5 & \\
\hline
\end{tabular}

In terms of girth of the chest, swimmers also surpass jumpers in the water. So, at 11 years old the difference is $4.2 \mathrm{~cm}$, and at 12 years old $12.2 \mathrm{~cm}$. These differences are statistically significant and are due to the specifics of the sport. For swimmers, the size of the chest affects the vital capacity indicator (VC), which is closely related to the athletic performance in swimming. The annual growth from 11-12 years for young swimmers is $11.6 \mathrm{~cm}$, and for jumpers in the water only $1.5 \mathrm{~cm}$. According to Brock's index, swimmers also outperform jumpers in the water. So, at 11 years old, this indicator for girls-swimmers is 10.3 , while for jumpers in the water 7.8. By the age of 12 , the Broca index increases in subjects of both specializations and is 12.6 for swimming and 9.5 for representatives of diving (Table 1). This reflects the specifics of swimming as a sport: the higher the Brock index, the better the hydrodynamic qualities of the swimmer. For divers in the water, this indicator is not significant. Higher annual growths of the studied indicators of physical development may indicate an earlier entry of swimmers into the puberty period of development.

Table 2: Proportions of the body of girls $11-12$ years old, engaged in swimming and diving (in\%).

\begin{tabular}{|c|c|c|c|c|}
\hline \multirow[t]{2}{*}{ Indicators } & \multirow[t]{2}{*}{ Age (years old) } & \multirow{2}{*}{$\begin{array}{c}\text { Swimmers } \\
\mathrm{X} \pm \sigma\end{array}$} & \multirow{2}{*}{$\begin{array}{l}\text { Jumpers in the water } \\
\qquad \mathrm{X} \pm \sigma\end{array}$} & \multirow[t]{2}{*}{$\mathbf{P}$} \\
\hline & & & & \\
\hline \multirow[t]{2}{*}{ Body weight / body length } & 11 & $23,9 \pm 1,3$ & $22,2 \pm 0,3$ & $<0,05$ \\
\hline & 12 & $29,1 \pm 1,2$ & $22,7 \pm 0,3$ & $<0,01$ \\
\hline \multirow{2}{*}{ Chest circumference / body length } & 11 & $49,2 \pm 0,5$ & $48,4 \pm 0,4$ & $<0,05$ \\
\hline & 12 & $51,7 \pm 1,5$ & $49,3 \pm 0,3$ & $<0,05$ \\
\hline \multirow[b]{2}{*}{ Shoulder Width / Body Length } & 11 & $22,6 \pm 1,4$ & $20,4 \pm 0,3$ & $<0,01$ \\
\hline & 12 & $22,3 \pm 1,3$ & $22,1 \pm 0,2$ & $>0,05$ \\
\hline \multirow{2}{*}{ Arm Length / Body Length } & 11 & $45,5 \pm 1,5$ & $43,3 \pm 0,1$ & $<0,05$ \\
\hline & 12 & $45,1 \pm 1,7$ & $43,8 \pm 0,2$ & $<0,05$ \\
\hline
\end{tabular}

of sports swimming $(13.8 \mathrm{~cm})$, compared with divers in water $(3.3 \mathrm{~cm})$ (Table 1$)$. Comparison of body mass indicators of girls 11-12 years old, engaged in swimming and diving, shows that at 11 years of age, swimmers reliably surpass jumpers in water by $3.8 \mathrm{~kg}$, and at 12 years old the difference is more significant and equal to $13.9 \mathrm{~kg}$ Accordingly, the annual increments also change, which are $11.6 \mathrm{~kg}$ for swimmers and only $1.5 \mathrm{~kg}$ for jumpers in the water.
Assessment of body proportions was carried out by calculating the ratio of body weight, chestcircumference, shoulder width, arm and leg length to body length in \%. According to the proportions of the body of the girl, the swimmers noticeably differ from the jumpers into the water. So, the ratio of weight to body length in girls-swimmers increases from 11-12 years more significantly than in jumpers in the water. Also, high growths are observed in swimmers according to indicators characterizing the ratio of chest circumference to body length. The ratio of shoulder width to body length in 11-year-old swimmers is significantly higher than that of jumpers in the water. However, by age 12, the differences become statistically unreliable. A study of the body proportions of girls aged 11-12 years suggests that swimmers have longer limbs compared to divers in the water. The ratio of arm length to body length at the age of 11 years is $45.5 \%$ for them, and for jumpers in the water - $43.3 \%$. At 12 years old, respectively, $45.1 \& 43.8 \%$. The same trend persists in relation to leg length to body length (Table 2). 
Journal of Physical Fitness, Medicine \& Treatment in Sports

Leg length / body length

\begin{tabular}{|l|l|}
\hline 11 & \\
\hline 12 & \\
\hline
\end{tabular}

An analysis of the body mass components of the studied groups showed that water jumpers are superior to swimmers in muscle tissue already at the age of 12 , although at 11 years old, these indicators were lower. However, the differences between them are not significant. A comparison of bone mass also indicates a heavier skeleton of jumpers in the water. At the same time, the differences in swimmers and jumpers in water in terms of bone mass are 3.1 at 11 years old, and at $3.3 \%$ at 12 years, and the significance of the differences reaches significant values. The

Table 3: Comparative data on the composition of body weight (\%) girls 11-12 years old, engaged in swimming and diving.

\begin{tabular}{|c|c|c|c|c|}
\hline \multirow{2}{*}{ Indicators } & \multirow{2}{*}{ Age(years old) } & Swimmers & Jumpers in the water & \multirow{2}{*}{$\mathbf{P}$} \\
\hline & & $X \pm \sigma$ & $X \pm \sigma$ & \\
\hline \multirow{2}{*}{ Muscle mass \% } & 11 & $47,0 \pm 3,7$ & $46,4 \pm 3,0$ & $>0,05$ \\
\hline & 12 & $43,9 \pm 3,5$ & $50,3 \pm 6,6$ & $>0,05$ \\
\hline \multirow{2}{*}{ Bone mass $\%$} & 11 & $15,0 \pm 1,6$ & $20,9 \pm 1,1$ & $>0,05$ \\
\hline & 12 & $19,8 \pm 1,6$ & $21,2 \pm 3,6$ & $>0,05$ \\
\hline \multirow{2}{*}{ Fat mass $\%$} & 11 & $17,4 \pm 5,6$ & $5,9 \pm 1,7$ & $<0,05$ \\
\hline & 12 & $17,7 \pm 6,0$ & $6,2 \pm 2,1$ & $<0,05$ \\
\hline \multirow{2}{*}{ Active body weight $\%$} & 11 & $65,3 \pm 2,7$ & $67,3 \pm 1,5$ & $>0,05$ \\
\hline & 12 & $63,7 \pm 4,2$ & $71,5 \pm 1,8$ & $>0,05$ \\
\hline
\end{tabular}

\section{Conclusion}

Thus, the study allowed us to identify differences in the physical development of girls-swimmers and jumpers in the water from 11 years of age. These differences, in our opinion, are associated both with sports selection and with the influence of sports specialization. And by the age of 12 , the difference in most indicators becomes more pronounced. It was revealed that girls' swimmers significantly surpass their peers in the water in terms of length and body weight, chest circumference, and Brock's index. Characteristic for swimmers is a more pronounced increase in the annual growth of the studied indicators from 11-12 years, which is probably due to their earlier entry into puberty. This is confirmed by the established differences in the proportions of the body of swimmers and jumpers into the water.

The body mass composition of the studied groups of athletes characterizes the divers in the water as athletically folded, as evidenced by higher rates of active body weight (bone + muscle component) compared to swimmers, and swimmers surpass them in fat mass. The revealed differences between girls specializing in swimming and diving indicate the presence of structural features of the body of athletes, which should be considered in the process of sports selection. same is confirmed by the data of active body weight, which is significantly higher among jumpers in the water in the studied groups (Table 3). As for the fat component, in swimmers it is more pronounced than among jumpers in the water. So, at 11 years old the difference is $12.1 \%$, at 12 years old $-12.6 \%$. This is due to the need for swimmers to stay in the water for a long-time during training, stimulates the body to form protection against hypothermia, and increases body buoyancy

\section{References}

1. Tumanyan GS, Martirosov EG (1976) Physique and sport. Moscow: Physical Culture and Sports 239pp.

2. Bulgakova N Zh (1986) Selection and training of young swimmers. Physical education and sport 191c.

3. Bulgakova N Zh, Popov OI, Chebotareva IV (2009) Age periods of formation of a swimmer's morphotype at the stages of longterm training. Materials of the international scientific conference "Physiology of Human Development"97-99.

4. Raspopova EA, Panasyuk TV (2011) The role of morphofunctional criteria for the selection of jumpers in the water at various stages of a long-term training process Materials. $2^{\text {nd }}$ regional. interuniversity. scientific and practical conference. "Modern education, physical education, sports and tourism" 80-83.

5. Timakova TS (2018) Factors of sports selection or Who becomes the Olympic champion. p287.

6. Raspopova EA, Panasyuk TV, Shovgenya N (2005) Features of the correlation between the dynamics of sports achievements and the pace of biological development of male divers in the water. All-Russian jubilee scientific-practical conference "Problems and prospects of development and sports 311-317.

7. Bulgakova N Zh (2010) Level of maturation and age zones of the most intensive growth rates of somatic and functional indicators as a criterion for the orientation of training XIV International Scientific Congress "Modern Olympic Sports and Sports for All" Congress materials. 1: S388-391. 
Your next submission with Juniper Publishers will reach you the below assets

- Quality Editorial service

- Swift Peer Review

- Reprints availability

- E-prints Service

- Manuscript Podcast for convenient understanding

- Global attainment for your research

- Manuscript accessibility in different formats

( Pdf, E-pub, Full Text, Audio)

- Unceasing customer service

Track the below URL for one-step submission

https://juniperpublishers.com/online-submission.php 